\title{
Recurrent lower gastrointestinal bleeding in an 87-year-old woman
}

\author{
Ilimbek Beketaev, ${ }^{1}$ Patrick R Reardon, ${ }^{1}$ Ekene I Okoye, ${ }^{2}$ Lee M Morris ${ }^{1}$
}

'Department of Surgery, Houston Methodist Hospital, Houston, Texas, USA

${ }^{2}$ Clinical Pathology and Genomic Medicine, Houston Methodist Hospital, Houston, Texas, USA

\section{Correspondence to}

Dr Lee M Morris,

Immorris@houstonmethodist. org

\section{Accepted 5 December 2017}

\section{DESCRIPTION}

An 87-year-old woman presented to an outside hospital with a complaint of bright red blood per rectum (BRBPR), where her haemoglobin was found to be $4.6 \mathrm{~g} / \mathrm{dL}$. An extensive gastrointestinal (GI) work was performed, including oesophagogastroduodenoscopy, colonoscopy and a video capsule endoscopy, followed by a superior mesenteric artery (SMA) angiogram which showed no active extravasation. The patient continued to have BRBPR and was transferred to our hospital for further work-up. Her medical history was significant for hypertension, hyperlipidaemia and coronary artery disease. Her surgical history included knee arthroplasty, hernia repair, hysterectomy,

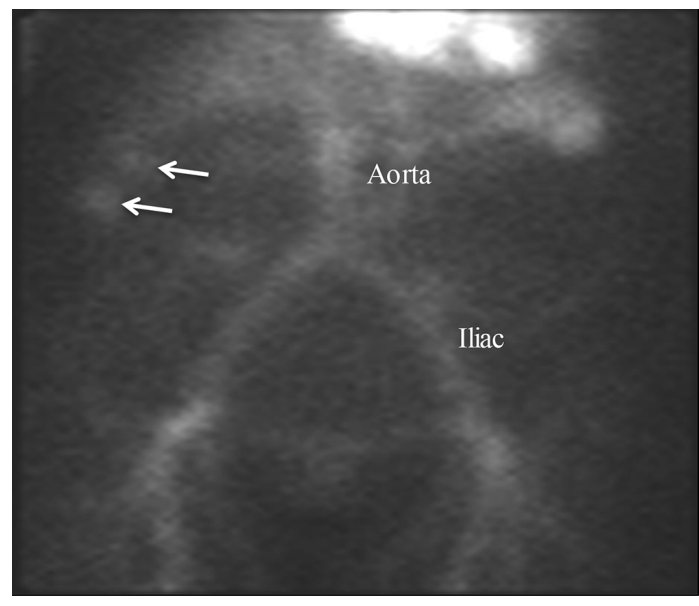

Figure 1 Nuclear medicine gastrointestinal bleeding study shows right colon bleeding.
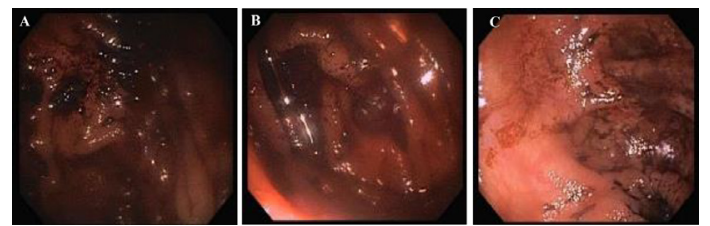

Figure 2 Colonoscopy findings.
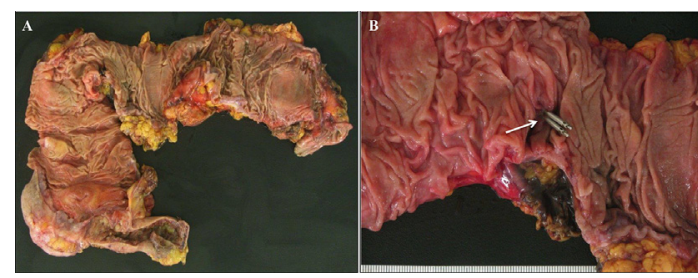

Figure 3 (A) Gross appearance of the colon resected. (B) A metal probe is used to highlight a diverticulum.

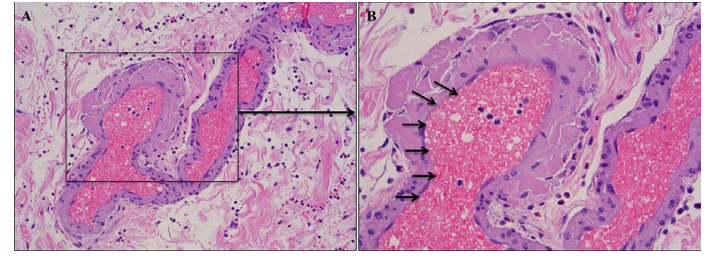

Figure 4 Histopathological findings of colon walls. Submucosal vessel with amyloid deposition. Note the presence of pink, amorphous material within the vessel wall, consistent with amyloid. (A) Low magnification (×200). (B) High magnification ( $\times 400)$.

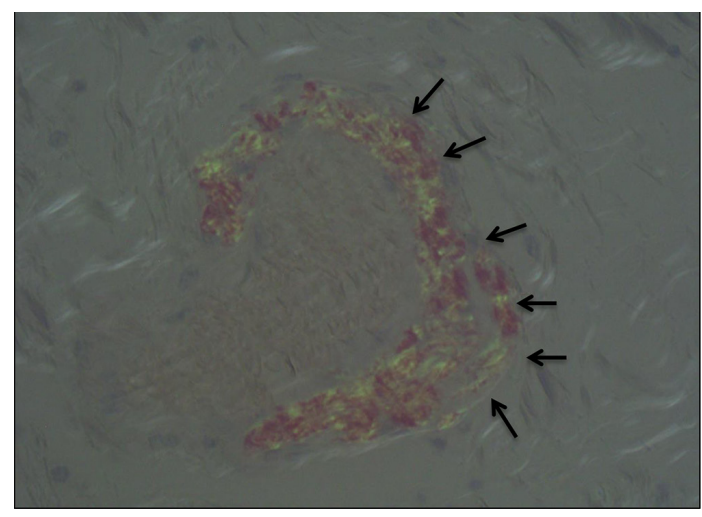

Figure 5 Congo red stain under polarised light highlights the amyloid deposits within the vessel wall, which have an apple-green hue.

cholecystectomy and appendectomy. Physical examination of the abdomen was soft, non-distended and non-tender. On transfer, a CT enterography was obtained and could not identify the source of bleeding but did note some stenosis of the superior mesenteric artery (SMA). A colonoscopy was then performed, which revealed old blood in her colon, but no active bleeding was found. A subsequent nuclear tagged red blood cell scan showed some extravasation in the right upper quadrant (figure 1), but the precise location of the small bowel versus the colon could not be made. Due to continued BRBPR and requiring additional blood transfusions, the patient was taken to the operative room for an interrogation of the colon and small bowel with intraoperative upper and lower endoscopy with possible laparoscopic-assisted small bowel enteroscopy. The upper endoscopy showed normal upper GI anatomy without any signs of bleeding. During the lower endoscopy, there was some old blood found in the proximal transverse colon; however, a complete colonoscopy could not be performed (figure 2). Therefore, exploratory 


\section{Learning points}

- Gastrointestinal (GI) diseases that cause lower gastrointestinal bleeding (LGIB) are more common in the elderly, and include vascular ectasia, diverticulosis coli, ischaemic colitis and colonic neoplasms. In Western Europe and USA diverticulosis coli is one of the most common causes of LGIB. ${ }^{1}$

- Gl amyloidosis may be a rare manifestation of GI bleeding as well and has been linked to patients with a history of jejunoileal bypass, ${ }^{23}$ although in this case it is difficult to be sure that the amyloidosis was the causal factor in her $\mathrm{Gl}$ bleeding, as colonic ischaemia from a stenotic SMA may have contributed to her GI bleeding as well.

laparoscopy and a minilaparotomy were performed to bring up the terminal ileum for antegrade access to the right colon. During laparoscopic exploration, it was noted the patient had abnormal anatomy consistent with a jejunoileal bypass, which was not known prior to surgery. During the antegrade evaluation of her right colon, a few right-sided diverticula were found and an area of mucosal bleeding was noted in the right colon, which was clipped endoscopically. The small bowel was also interrogated with the colonoscope, and there was no blood found in the small bowel proximally. Despite the clips placed in the right colon, bleeding persisted and so a laparoscopic right haemicolectomy was performed (figure 3). Postoperatively, the patient did well and had no further GI bleeding episodes, and her haemoglobin remained stable without additional need for blood transfusions. She admitted postoperatively that she had previously underwent a weight loss procedure in 1985 consistent with a jejunoileal bypass. Histopathological examination of the resected colonic specimen revealed amorphous, pink deposits in the submucosal vessels with amyloid deposition, consistent with GI amyloidosis (figure 4). To confirm GI amyloidosis, the deposits were positive for Congo red staining and characteristic apple-green birefringence under polarised light(figure 5).

Contributors IB wrote the manuscript and prepared the images and figures. PRR reviewed and edited the manuscript. ElO prepared the images. LMM wrote the manuscript and prepared the images and figures.

Competing interests None declared.

Patient consent Obtained.

Provenance and peer review Not commissioned; externally peer reviewed.

(C) BMJ Publishing Group Ltd (unless otherwise stated in the text of the article) 2017. All rights reserved. No commercial use is permitted unless otherwise expressly granted.

\section{REFERENCES}

1 Chait MM. Lower gastrointestinal bleeding in the elderly. World J Gastrointest EndosC 2010:2:147-54.

2 Ali MF, Patel A, Muller S, et al. Rare presentation of primary (AL) amyloidosis as gastrointestinal hemorrhage without systemic involvement. World J Gastrointest Endosc 2014;6:144-7.

3 Cornelis T, Bammens B, Lerut E, et al. AA amyloidosis due to chronic oxalate arthritis and vasculitis in a patient with secondary oxalosis after jejunoileal bypass surgery. Nephrol Dial Transplant 2008;23:3362-4.

Copyright 2017 BMJ Publishing Group. All rights reserved. For permission to reuse any of this content visit http://group.bmj.com/group/rights-licensing/permissions.

BMJ Case Report Fellows may re-use this article for personal use and teaching without any further permission.

Become a Fellow of BMJ Case Reports today and you can:

- Submit as many cases as you like

- Enjoy fast sympathetic peer review and rapid publication of accepted articles

- Access all the published articles

- Re-use any of the published material for personal use and teaching without further permission

For information on Institutional Fellowships contact consortiasales@bmjgroup.com

Visit casereports.bmj.com for more articles like this and to become a Fellow 